\title{
Development of a tool to measure patients' satisfaction of hospital foodservice in a government hospital
}

\author{
Mariem Boughoula ${ }^{1}$, Rosita Jamaluddin ${ }^{1 *}$, Nurul Aqmaliza Abd Manan ${ }^{1}$, Hazizi \\ Abu Saad ${ }^{1}$ \& Muhammad Sharim Ab Karim²
}

${ }^{1}$ Department of Nutrition and Dietetics, Faculty of Medicine and Health Sciences, Universiti Putra Malaysia, Selangor, Malaysia; ${ }^{2}$ Department of Food Service and Management, Faculty of Food Science and Technology, Universiti Putra Malaysia, Selangor, Malaysia

\begin{abstract}
Introduction: Dissatisfaction towards the quality of foodservice can affect several important aspects such as nutritional intake and financial burden. The effect of dissatisfaction towards nutritional aspect can be observed via a decline in dietary intake. Therefore, reliable and valid questionnaires are important to measure patients' satisfaction with hospital foodservice. The main purpose of this study was to investigate the construct validity and reliability of a developed questionnaire in a local setting. Methods: A questionnaire adapted from previous studies and consisting of 27 statements from four dimensions, was administered to a total of 277 hospitalised patients in a government hospital. Factor analysis and reliability analysis were conducted using SPSS version 25. Results: Principal component of factor analysis revealed that the final questionnaire contained four main foodservice dimensions, namely food properties, staff and meal service reliability, customisation, and physical and social aspects. The reliability analysis revealed that the Cronbach's alpha value ranged from 0.55 to 0.84 for these foodservice dimensions. The analysis showed that the alpha value differed from one dimension to another such as food properties $(\alpha=0.84)$, staff and meal service reliability $(\alpha=0.67)$, customisation $(\alpha=0.69)$ and physical and social aspects $(\alpha=0.55)$. Conclusion: Twenty-seven questionnaire items were retained because their factor loadings were greater than 0.35. Therefore, the questionnaire on patients' satisfaction towards hospital foodservice was considered reliable and valid. The classification of the four dimensions provided detailed information of the satisfaction level, relationship and influence on the foodservice dimensions, which contributed to satisfaction towards hospital foodservice.
\end{abstract}

Keywords: Patients' satisfaction, hospital food, hospital foodservice, reliability, validity, factor analysis

\section{INTRODUCTION}

The importance of patients' satisfaction towards foodservice stems from its ability to influence the overall satisfaction on hospital care quality (Demir \& Celik,
2002). The term satisfaction can be defined as the experience of a customer using a service and can evoke positive feelings (Namkung \& Jang, 2007). In health care service, patients' satisfaction

\footnotetext{
*Corresponding author: Associate Professor Dr. Rosita Jamaluddin

Faculty of Medicine and Health Sciences, Department of Nutriton and Dietetics, Universiti Putra Malaysia, Serdang, Selangor, Malaysia

Tel: (6)(03)89472467; Fax: (6)(03)89426769; E-mail: rositaj@upm.edu.my

doi: https://doi.org/10.31246/mjn-2019-0047
} 
can also be defined as an evaluation of a patient's experience of health care services via their cognitive and emotional reactions (Keegan \& McGee, 2003). From the definition, satisfaction is always related with service. Thus, this indicates that a strong relationship exists between patients' satisfaction and health care service, especially foodservice (Wright, Comelly \& Capra, 2006).

Modernisation of the healthcare industry has shown many improvements in almost every aspect of the component. In a hospital setting, the foodservice department often undergoes upgrading in almost every aspect to improve quality, as well as patients' satisfaction. The influence of patients' satisfaction towards foodservice affects the overall satisfaction towards hospital care quality (Ganasegeran et al., 2015). Several studies have shown that the satisfaction towards hospital foodservice is influenced by different factors such as food quality, interpersonal dimension, and physical environment (Naithani et al., 2009; Hartwell, Edwards \& Symonds, 2006; Stanga et al., 2008). The measurement of patients' satisfaction becomes an important tool to measure the quality given to patients. However, the measurement of satisfaction in a hospital setting is difficult to analyse because it involves the degree of feeling towards a service and is influenced by other factors.

There are various tools often used to measure patients' satisfaction with hospital food or foodservice. (Deluco \& Cremer, 1990; Dube, Trudeau \& Belanger, 1994; Capra et al., 2005). The earliest tool used to evaluate the satisfaction towards a service is the Service Quality (SERVQUAL) model. This model rose from a study by Parasuraman, Zaithaml \& Berry (1988) in which the tool stated that the dimensions of customer satisfaction towards a service were responsiveness, assurance, reliability, empathy and tangibility. However, because it was derived from a service/hospitality setting rather than a healthcare setting, SERVQUAL failed to produce clear dimensions for hospital service because the evaluation of hospital service by patients is different when compared with customers from other service industries (Babakus \& Mangold, 1991; Johns \& Howard, 1998).

Shortly after SERVQUAL was developed, Deluco \& Cremer (1990) conducted a telephone interview with 223 randomly selected adults in Ohio to determine consumers' perceptions on the quality of hospital foods, foodrelated service, clinical service, and their importance. Four years later, Dube et al. (1994) developed a questionnaire to determine the overall satisfaction with meals and with foodservice, and satisfaction with 26 specific foodservice attributes. Food quality was the main predictor of the survey. Seven dimensions representing patients' perceptions of foodservice were identified: food quality, service timeliness, service reliability, food temperature, attitude of the staff who deliver the menus, attitude of the staff who serve the meals, and customisation (Dube et al., 1994).

The Acute Care Hospital Foodservice Patient Satisfaction Questionnaire (ACHFPSQ) developed by Capra et al. (2005) was the first reliable and valid questionnaire to measure patients' satisfaction towards hospital foodservice (Capra et al., 2005). The questionnaire was initially developed to measure patients' satisfaction with acute care hospital foodservice and contained 16 statements relating to four factors describing food quality, meal service quality, staff/service issues and physical environment (Capra et al., 2005). Since then, the tool had been used widely to measure patients' satisfaction with 
hospital foodservice because it was considered to be a comprehensive and complete tool.

Numerous satisfaction surveys had been performed in Malaysia. However, the results of these studies were too general without studying the actual causes that contribute to dissatisfaction towards foodservice. This study will identify the actual factors that are associated with dissatisfaction in hospital foodservice. The importance of this tool is that it can be useful for assessing the level of satisfaction towards hospital foodservice, as well as patients' perceptions towards hospital meals. Dietitians can use the results obtained as a reference to improve or modify any part of the foodservice components in order to enhance the quality of hospital meals and to create a positive perception among patients towards hospital meals, resulting in an increase in food consumption. This research will create awareness among hospital foodservice personnel on the actual foodservice dimensions that influence food intake. Thus, the specific dimensions identified can ensure that meals provided meet the requirement for patient recovery. In addition, the tool will hopefully enable these personnels to address issues pertaining to the high volume of food wastage. Data from this study can be used as baseline for further research regarding hospital foodservice systems.

The tool used in this study was based on international studies and the questions were modified to fit the local hospital setting. There is no published evidence that the tool used is valid and reliable for hospital setting in Malaysia. Hence, this study was conducted to determine the construct validity and reliability of the questionnaire using factor analysis and reliability analysis.

\section{MATERIAL AND METHODS}

\section{Study design and data collection}

This is a cross-sectional study that was conducted in a 620-bed urban government hospital in Malaysia. The duration for data collection for this study was three months. Prior to data collection, permission was obtained from the Ministry of Health (MOH) Malaysia and the Director of the hospital. Ethical approval was granted by the Medical Research Ethics Committee of the $\mathrm{MOH}$ Malaysia and the Medical Research Ethics Committee of the Faculty of Medicine and Health Sciences, Universiti Putra Malaysia. Data collection involved hospitalised patients who fulfilled the inclusion criteria. Patients were recruited based on the following inclusion criteria: consumed normal diet from hospital, stayed at least two days in the ward and able to give solid opinion. However, patients were excluded from the study if they consumed therapeutic diet, received enteral or parenteral nutrition, nil by mouth, and/or were unable to communicate well. The collected data were patients' specific characteristics (age, gender), and questionnaire on patients' satisfaction towards foodservice. A total of 562 respondents were interviewed. Out of that, 285 were unable to complete the questionnaire due to various reasons. As a result, only 277 respondents successfully completed the questionnaire. Approximately 116 patients were in second-class wards, while 161 were in third-class wards.

\section{Measurements}

In this study, the satisfaction of respondents towards hospital foodservice was measured using a questionnaire adapted from studies by Capra et al. (2005), Hartwell, Edwards 
\& Beavis (2007), Hwang \& Desombre (2003), O'Hara et al. (1997), and Dube et al., (1994). Initially, there were five dimensions and a total of 31 items applied and used to measure the satisfaction level among hospitalised patients.

Quality of food is an important dimension because this factor normally gives a major influence on patients' satisfaction during hospitalisation (Dube et al. 1994; Lau \& Gregoire 1998; Wright et al., 2006). In addition, according to previous literatures, the interaction or communication between staffs and patients also influences the satisfaction towards foodservice (Dubé et al., 1994). The delay in food delivery and serving by service staffs can make patients less satisfied towards the quality of service (Stanga et al., 2003). Some studies suggested that interpersonal or service aspects were the most significant in contributing towards patients' satisfaction (Deluco \& Cremer, 1990; Hartwell et al., 2007). Physical environment factors, such as smell, colour, lighting and ambient temperature, eating location and social variables can also affect patients' perceptions towards hospital foodservice (Capra et al., 2005; Hartwell et al., 2006). Finally, other important foodservice dimensions are timeliness and reliability. Dubé et al. (1994) stated that timeliness is related with the duration for eating and the time for staff to pick up the tray, whereas reliability is more related to punctuality of the foodservice and service hours.

Based on the literature discussed previously, five dimensions were selected as follows: 1. Food quality, 2. Timeliness and reliability, 3. Staff issue 4. Meal service quality and 5. Physical environment. There were fourteen questions in the food quality dimension. The questions were related with food texture, quality of fish and meat, temperature, food flavour and other food quality attributes. There were five questions in the staff issue dimension. The questions were related to courtesy and attitude of the staffs, punctuality of the staff who served the food and other related questions. There were seven questions in the dimension of timeliness and reliability. The questions were mostly related with the suitability of mealtimes and the time provided to finish the foods. The meal service dimension had three questions and most of them were related with the quality of cutlery and crockery, and options given to patients. The last dimension was the environmental presentation containing two questions in this dimension. The questions were related with the smell and noise of the ward.

Items labelled as FQ1, FQ2, FQ3, FQ4, FQ7, FQ9, FQ10, FQ11, FQ12, SI1, SI2, SI4, MS1, MS2, PE1 and PE2 were adapted from Capra et al. (2005), FQ5 and FQ6 were adapted from Hartwell et al. (2007), eight items labelled as FQ13, FQ14, TR5, TR6, TR7, SI3, S15 and MS3 were adapted from Hwang \& Desombre (2003), while only four items labelled as TR1, TR2, TR3 and TR4 were adapted from Dube et al. (1994), and an item labelled as FQ8 was adapted from O'Hara et al. (1997).

The questions were modified to fit the hospital setting as presented in Table 1 . To measure satisfaction towards these foodservice dimensions, a five-point Likert scale was used as previously done by Capra et al. (2005). The scale was coded as "strongly dissatisfied", "dissatisfied", "average", "satisfied" and "strongly satisfied". The lowest value was coded as "strongly dissatisfied," while the highest value was coded as "strongly satisfied". A score was given based on the answer - strongly dissatisfied was scored as 1, dissatisfied was scored as 2 , average was scored as 3, satisfied was scored as 4 and strongly satisfied was scored as 5 . The composite score, that is the sum of all dimension scores, 
Table 1. The initial construct dimensions and items

\begin{tabular}{llc}
\hline Dimension & Items & Label \\
\hline Food quality & The meal tastes nice & FQ1 \\
& The fruit served is fresh & FQ2 \\
& I like the way the vegetables are cooked & FQ2 \\
The meat quality (chicken, fish) served to me is the best & FQ4 \\
The texture of meals are good and suitable for my condition & FQ5 \\
Portion size of my meals are suitable and enough for me & FQ6 \\
The meals have excellent and distinct flavours & FQ7 \\
The drinks served are just at the right temperature & FQ8 \\
The hot foods are just at the right temperature & FQ9 \\
The cold foods are just at the right temperature & FQ10 \\
I can choose healthy foods in the hospital & FQ11 \\
The colour of meals is attractive & FQ12 \\
The smell of meal is nice and good & FQ13
\end{tabular}

Timeliness and The meal time for breakfast is suitable $\quad$ TR1 reliability The meal time for lunch is suitable $\quad$ TR2

The meal time for tea is suitable TR3

The meal time for dinner is suitable $\quad$ TR4

The meals are served punctually according to schedule TR5

The meals are served exactly as ordered $\quad$ TR6

The time is enough to finish the meal TR7

Staff issue $\quad$ The staffs who deliver and take away my meal are friendly and $\quad$ SI1

polite

The staffs who deliver and take away my meal are neat and $\quad$ SI2

clean

The staffs (nurse or foodservice personnel) are willing to help SI3

patient with eating difficulties

The staffs have explained to me about my diet $\quad$ SI4

The staffs only take my tray after I finish eating $\quad$ SI5

Meal service The crockery and cutlery in my tray is in good condition MS1

quality I like to be able to choose different sized meals

Other meal should be provided when patient misses the regular MS3

meal service

Physical The ward's smell stops me from enjoying my meal PE1

environment The ward's noise disturbs me from enjoying meal PE2

was used as further calculation for the overall score. All the items were worded positively. The list of questions used in the study is presented in Table 1.

\section{Data analysis}

Determination of the validity of the scale Principle component analysis (PCA) was used to determine the underlying dimensions of the questionnaire. Orthogonal transformation was used to convert the construct variables/ items into a set of variables which were most related to each other. This analysis was used to calculate the maximum total of variance in the data 
Table 2. Distribution of patients' socio-demographic characteristics $(N=277)$

\begin{tabular}{|c|c|c|c|}
\hline Socio-demographic variables & $n$ & $\%$ & Mean $\pm S D$ \\
\hline Age (years) & & & $34.96 \pm 12.32$ \\
\hline$\leq 20$ & 34 & 12.3 & \\
\hline $21-30$ & 106 & 38.3 & \\
\hline $31-40$ & 49 & 17.7 & \\
\hline $41-50$ & 43 & 15.5 & \\
\hline$\geq 51$ & 45 & 16.2 & \\
\hline \multicolumn{4}{|l|}{ Gender } \\
\hline Male & 145 & 52.3 & \\
\hline Female & 132 & 47.7 & \\
\hline \multicolumn{4}{|l|}{ Education level } \\
\hline No education or primary & 31 & 11.2 & \\
\hline Secondary & 161 & 58.1 & \\
\hline Tertiary & 85 & 30.7 & \\
\hline \multicolumn{4}{|l|}{ Occupational sector } \\
\hline None & 79 & 28.5 & \\
\hline Government & 78 & 28.2 & \\
\hline Household income (RM) & & & $2618.38 \pm 1683.40$ \\
\hline$\leq 2000$ & 141 & 50.9 & \\
\hline $2000-4000$ & 97 & 35.0 & \\
\hline $4001-6000$ & 26 & 9.4 & \\
\hline$\geq 6001$ & 13 & 4.7 & \\
\hline \multicolumn{4}{|l|}{ Marital status } \\
\hline Single & 89 & 32.1 & \\
\hline Married & 181 & 65.3 & \\
\hline Divorced & 7 & 2.5 & \\
\hline
\end{tabular}

set with the smallest value of mutually independent underlying statement or factor within each factor (Norman \& Streiner, 2000; Pallant, 2005). The eigenvalue or total amount of variance explained by each factor that was used to separate the factors from each other was also determined. An eigenvalue of greater than 1 was used to separate the factors; a factor with a value of $<1$ was considered unfitting. Capra et al. (2005) however accepted a factor that was $<1$.

Several assumptions were examined before conducting the analysis. The sufficiency of sample size must meet the assumption. There are different suggestions regarding the suitability of a sample size for analysis. However, for this study, the sample size was calculated based on five cases or participants per variable (Allen \& Bennett, 2008). Another assumption that needed to be considered was the strength of the relationship between items, which can be observed via a correlation matrix showing at least some correlation, at $r=0.3$ or above (Tabachnik \& Fidell, 2007). Other than that, the factorability of the data can also be measured using the Bartlett's Test of Sphericity and Kaiser-Meyer-Olkin (KMO) to measure sampling adequacy. The Bartlett's Test of Sphericity should be statistically significant at $p<0.05$ and the KMO value $\geq 0.6$ to be considered appropriate for the conduct of factor analysis in a study where orthogonal rotation is applied. This rotation is able to produce outcomes that are easier to 


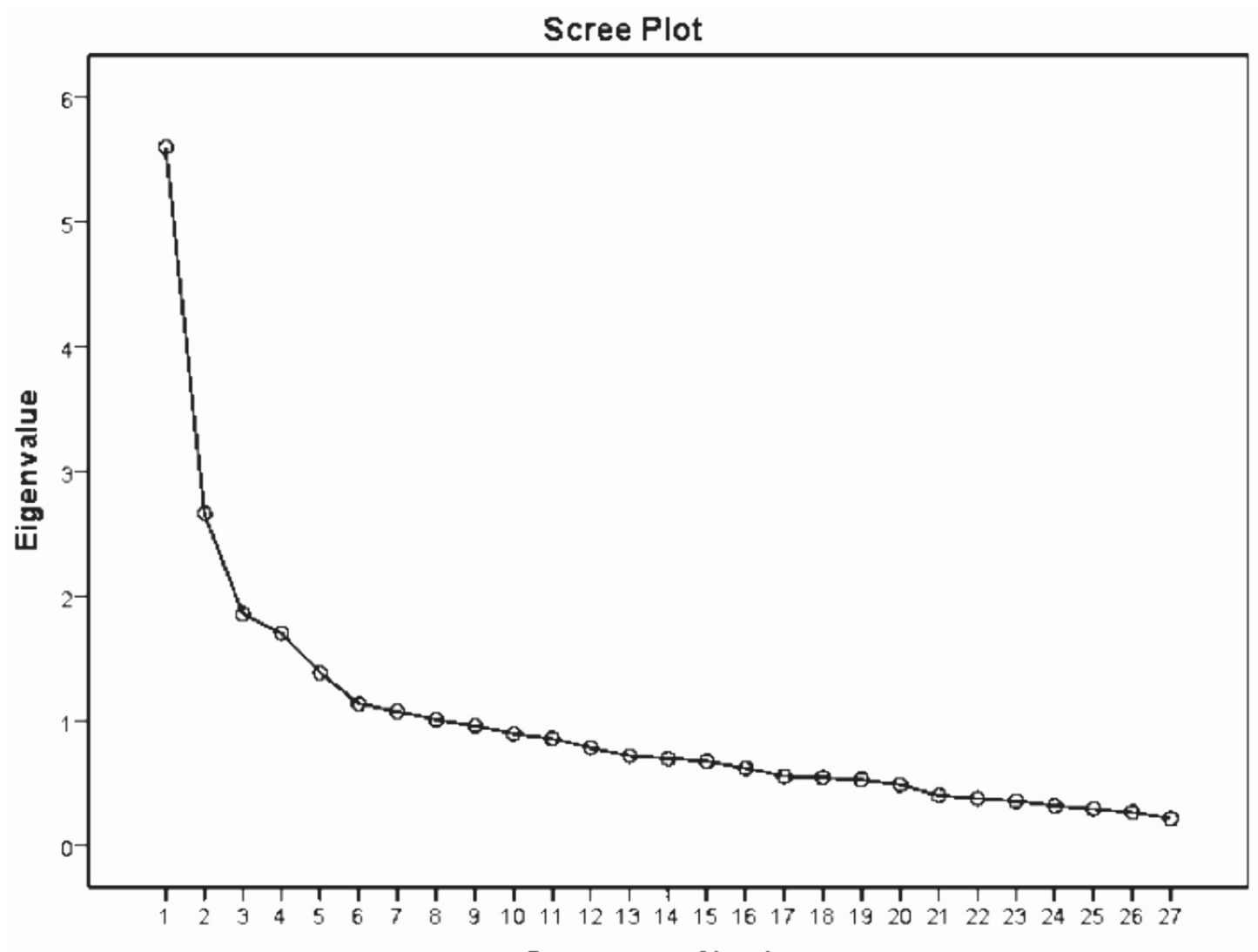

Component Number

Figure 1. Scree plot

interpret and report, while the oblique rotation produces outcomes that are more difficult to interpret, describe and report (Tabachnik \& Fidell, 2007). The Varimax method is the most common orthogonal rotation used because it is able to reduce the number of items, which have high loading on each factor.

Determination of the reliability of the scale

Reliability analysis was conducted to examine the Cronbach's alpha of these new dimensions. According to the rule of thumb proposed by George \& Mallery (2003), a value of $\alpha>0.8$ indicates good internal consistency of the items in the scale. However, a Cronbach's alpha value $\geq 0.5$ is considered to meet the minimum level of reliability (Hinton et al., 2004). In this study, a Cronbach's alpha value of above 0.5 was accepted.

\section{RESULTS}

A total of 380 hospitalised patients participated in the study. However, only 277 patients (145 males and 132 females) were able to complete the study. Age ranged from 18 to 59 years old, with the mean age being $34.96 \pm 12.32$ years old. The socio-demographic characteristics of the patients are presented in Table 2.

Initial principle component analysis was used to assess the suitability of the data. The examination of correlation matrix showed the presence of many coefficients of $\geq 0.3$. The value of KMO 
was 0.7 , which was higher than the recommended value of 0.6. Bartlett's Test of Sphericity was also statistically significant (chi-square $=2235.71$, $p<0.001)$. At the initial stage, PCA revealed eight factors with eigenvalues $>1$ and the percentage of total variance explained were $20.74 \%, 9.86 \%, 6.89 \%$, $6.31 \%, 5.13 \%, 4.21 \%, 3.98 \%$ and $3.75 \%$ respectively. The assessment of the scree plot showed that four factors should be retained as shown in Figure 1.

The rotation of four dimensions from the questionnaire showed that a few items were presented in two dimensions or were moved from the original dimension to another. Items with a factor loading of $<0.30$ were removed from the dimensions. The underlying dimensions were labelled as food properties, staff and meal service reliability, mealtime and physical-social issue, customisation, meal service and staff issue. The statements that appeared in each factor or dimension were considered fit based on the eigenvalue and the total of variance explained by the statement. A summary of the results is presented in Table 3.

In this study, there were 27 individual statements to be rated by patients. The individual score of the dimension was rated using five-point scales with 5 as the maximum point and 1 as the minimum point. The score of individual statements were evaluated. In the present study, the lowest scale used was 1 for highly dissatisfied, 2 for dissatisfied, 3 for moderate, 4 for satisfied and 5 as the highest scale for highly satisfied. If the mean score of an individual statement was $<2.50$, it was considered as dissatisfied. A mean score $\geq 2.50$ but $<3.50$ was considered moderate and a score of $\geq 3.50$ was considered satisfactory. The distribution of means for individual statements are presented in Table 4.
The dimension score was calculated using the summation of mean scores of individual statements. Four dimension scores represented four foodservice dimensions. As for the composite score, it was obtained by summation of the scores of four dimensions. Table 5 shows the distribution of dimension scores and their percentages. The findings indicated that there were three dimensions which were able to obtain above $70.00 \%$ in their composite score percentage. The dimension with the highest score was customisation $(15.35 \pm 1.84)$ with scores ranging from 8 to 20. The second highest score was the dimension of physical-social issue (15.34 \pm 1.68$)$ with scores ranging from 9 to 20. The third highest score was the dimension of meal service and staff issue $(25.95 \pm 3.01)$ with scores ranging from 14 to 34 . The food properties dimension (39.99 \pm 6.16$)$ was only able to achieve $66.67 \%$ of the maximum possible score. The mean overall satisfaction towards hospital foodservice was $6.25 \pm 1.68$ with a score of $62.50 \%$. This indicated that the judgment of quality in foodservice dimensions were different from one another.

The results of the reliability analysis of the dimensions revealed that the Cronbach's alpha $(\alpha)$ value of the four dimensions after factor analysis were 0.84, 0.67, 0.69 and 0.55, respectively, which depicted good internal consistency of the scale for each dimension. In Table 3, the first statement under "staff and meal service reliability" (i.e. meals are served punctually according to schedule) was mentioned again in more details under the "mealtime" section. In addition, the first statement under the physical and social section (i.e. staffs who deliver and collect my meals are friendly and polite) was moved from the "staff issue" dimension to the physical and social dimension. 
Table 3. The dimensions of foodservice satisfaction and factor loadings for each item

\begin{tabular}{|c|c|c|c|}
\hline Items & $\begin{array}{l}\text { Factor } \\
\text { loading }\end{array}$ & Eigenvalue & $\begin{array}{c}\text { Variance } \\
\text { explained } \\
\text { by factor } \\
\text { (\%) }\end{array}$ \\
\hline Food properties & & 5.65 & 21.73 \\
\hline 1. The meal tastes nice & 0.58 & & \\
\hline 2. I like the way the vegetables are cooked & 0.60 & & \\
\hline $\begin{array}{l}\text { 3. The meat quality (chicken and fish) served to me is } \\
\text { the best }\end{array}$ & 0.50 & & \\
\hline $\begin{array}{l}\text { 4. The texture of meal is good and suitable for my } \\
\text { condition }\end{array}$ & 0.36 & & \\
\hline $\begin{array}{l}\text { 5. The portion size of the food is suitable and enough } \\
\text { for me }\end{array}$ & 0.42 & & \\
\hline 6. The meals have excellent and distinct flavours & 0.58 & & \\
\hline 7. The drinks served are just at the right temperature & 0.53 & & \\
\hline 8. The hot foods are just at the right temperature & 0.73 & & \\
\hline 9. The cold foods are just at the right temperature & 0.62 & & \\
\hline 10. I can choose healthy food in the hospital & 0.57 & & \\
\hline 11. The colour of meals is attractive & 0.58 & & \\
\hline 12. The smell of meals is nice and good & 0.58 & & \\
\hline Staff and meal service reliability & & 2.30 & 8.84 \\
\hline $\begin{array}{l}\text { 1. The meals are served punctually according to } \\
\text { schedule }\end{array}$ & 0.37 & & \\
\hline 2. The meals are served exactly as ordered & 0.55 & & \\
\hline $\begin{array}{l}\text { 3. The staffs who deliver and collect my meals are } \\
\text { neat and clean }\end{array}$ & 0.38 & & \\
\hline $\begin{array}{l}\text { 4. The staffs (nurse or foodservice personnel) are } \\
\text { willing to help patients with eating difficulties }\end{array}$ & 0.56 & & \\
\hline 5. The staffs have explained to me about my diet & 0.65 & & \\
\hline 6. The staffs only take my tray after I am done eating & 0.55 & & \\
\hline Mealtime & & 2.12 & 8.15 \\
\hline 1. The mealtime for breakfast is suitable & 0.77 & & \\
\hline 2. The mealtime for lunch is suitable & 0.86 & & \\
\hline 3. The mealtime for tea is suitable & 0.72 & & \\
\hline Physical and social & & 1.41 & 5.43 \\
\hline $\begin{array}{l}\text { 1. The staffs who deliver and collect my meals are } \\
\text { friendly and polite }\end{array}$ & 0.56 & & \\
\hline 2. The ward's smell stops me from enjoying my meals & 0.73 & & \\
\hline $\begin{array}{l}\text { 3. The ward's noise disturbs me from enjoying my } \\
\text { meals }\end{array}$ & 0.78 & & \\
\hline
\end{tabular}


Table 4. Distribution of the scores of each foodservice individual statement

\begin{tabular}{|c|c|}
\hline Foodservice dimension/Statement & $\begin{array}{c}\text { Score }^{+} \\
\text {Mean } \pm S D\end{array}$ \\
\hline \multicolumn{2}{|l|}{ Food properties } \\
\hline 1. The meal tastes nice & $3.23 \pm 0.77$ \\
\hline 2. I like the way vegetables are cooked & $3.09 \pm 0.97$ \\
\hline 3. The meat quality (chicken and fish) served to me is the best & $3.46 \pm 0.87$ \\
\hline 4. The texture of meals are good and suitable for my condition & $3.53 \pm 0.75$ \\
\hline 5. Portion size of my meals are suitable and enough for me & $3.95 \pm 0.64$ \\
\hline 6. The meals have excellent and distinct flavours & $3.11 \pm 0.80$ \\
\hline 7. The drinks served are just at the right temperature & $2.91 \pm 1.01$ \\
\hline 8. The hot foods are just at the right temperature & $3.38 \pm 0.85$ \\
\hline 9. The cold foods are just at the right temperature & $3.56 \pm 0.69$ \\
\hline 10. I can choose healthy food in the hospital & $3.39 \pm 0.92$ \\
\hline 11. The colour of my meals are attractive & $3.17 \pm 0.95$ \\
\hline 12. The smell of my meals are nice and good & $3.21 \pm 0.87$ \\
\hline \multicolumn{2}{|l|}{ Meal service and staff issue } \\
\hline 1. The mealtime for dinner is suitable & $3.72 \pm 0.68$ \\
\hline 2. The meals served punctually according to schedule & $3.61 \pm 0.78$ \\
\hline 3. The meals served exactly as ordered & $3.56 \pm 0.84$ \\
\hline 4. The staffs who deliver and collect my meals are neat and clean & $3.95 \pm 0.51$ \\
\hline $\begin{array}{l}\text { 5. The staffs (nurse or foodservice personnel) is willing to help patient } \\
\text { with eating difficulties }\end{array}$ & $3.85 \pm 0.62$ \\
\hline 6. The staffs have explained to me about my diet & $3.46 \pm 0.91$ \\
\hline \multicolumn{2}{|l|}{ Customisation } \\
\hline 1. The fruit served is fresh & $3.82 \pm 0.67$ \\
\hline 2. The mealtime for breakfast is suitable & $3.84 \pm 0.63$ \\
\hline 3. The mealtime for lunch is suitable & $3.89 \pm 0.60$ \\
\hline 4. The mealtime for tea is suitable & $3.79 \pm 0.65$ \\
\hline \multicolumn{2}{|l|}{ Physical and social } \\
\hline 1. The staffs who deliver and collect my meal are friendly and polite & $3.62 \pm 0.80$ \\
\hline 2. The hospital or ward scent stops me from enjoying my meals & $3.96 \pm 0.60$ \\
\hline 3. The noise at hospital or ward disturbs me from enjoying my meals & $3.74 \pm 0.81$ \\
\hline 4. The duration given to finish the meal is enough & $4.02 \pm 0.59$ \\
\hline
\end{tabular}

${ }^{\dagger}$ Mean score was based on the scale of 1 to 5

\section{DISCUSSION}

This study found four underlying dimensions of patients' satisfaction towards hospital foodservice. An observation on the first dimension indicated that most of the statements were related to food quality attributes. Based on two studies that had been conducted previously by Capra et al. (2005) and Hwang \& Desombre (2003), it was proposed that statements about food attributes (taste, temperature and aroma of food) could be classified as food properties. Based on that, the first dimension was labelled as food properties. 
Table 5 Distribution of dimension scores rated by patients

\begin{tabular}{lccc}
\hline Foodservice dimension & $\begin{array}{c}\text { Maximum possible } \\
\text { score }\end{array}$ & $\begin{array}{c}\text { Rated score } \\
\text { Mean } \pm S D\end{array}$ & Percentage (\%) \\
\hline Food properties & 60.00 & $39.99 \pm 6.16$ & 66.67 \\
Meal service and staff issue & 35.00 & $25.95 \pm 3.01$ & 74.14 \\
Customisation & 20.00 & $15.35 \pm 1.84$ & 76.75 \\
Physical-social issue & 20.00 & $15.34 \pm 1.68$ & 76.70 \\
Composite score & 135.00 & $96.30 \pm 9.17$ & 71.58 \\
\hline
\end{tabular}

The second dimension was labelled as meal service and staff issue because the statements were mostly related to staff and meal service reliability. This finding contradicted with the finding by Dube et al. (1994), which found that the dimensions of meal service reliability and staff issue were presented in two separate dimensions. However, a gap analysis found that the aspects of meal service and staff issue can be presented in one dimension (Hwang \& Desombre, 2003), consistent with this study.

The third dimension was labelled mealtime because the statements of the dimension was regarding the suitability of mealtime. Normally, mealtime is related with timeliness and reliability aspects (Hwang \& Desombre, 2003; Dube et al., 1994). The attribute of mealtime suitability also affects patients' perceptions during hospitalisation (Dube et al., 1994). Normally, meal times for hospitals in Malaysia are: breakfast at 7.00 a.m., lunch at 12.30 p.m., tea at 3.30 p.m. and dinner at 6.30 p.m. (Vijayakumaran, Eves \& Lumbers, 2010). Previous literature reported that patients commonly stated that the gap between meal times were too short or too long (Naithani et al., 2008). Inappropriate meal times tend to affect patients' perceptions (feeling unhappy with breakfast and dinner) on hospital foodservice (Vijayakumaran et al., 2010). However, in a study by Lassen, Kruse \& Bjerrum (2005), almost all patients were very satisfied with each meal time and only a minority of patients were dissatisfied. This indicted that the presence of meal time dimension is important in measuring satisfaction.

Physical-social issue dimension was labelled as the fourth dimension because the statements were mostly about meal time surroundings. According to Dickinson et al. (2005), there are three aspects which influence patients' perceptions towards hospital foodservice that needed to be considered. These aspects are physical environment, aesthetic, and social aspects. In comparison, the finding of the study was almost consistent with the finding by Hwang \& Desombre (2003) that social contact and environment aspects can be presented in the same dimension. However, Capra et al. (2005) found that the statements regarding noise, scent and condition of items on the tray were only present in the physical environment dimension. On the other hand, Abd Manaf and Phang (2007) found five items grouped under physical dimension, namely cleanliness of the ward, environment of the ward, management of visitors to the wards, condition of the bathrooms and toilets and noise in ward.

Findings of this study revealed that the food properties dimension was the strongest dimension $(\beta=0.392)$ contributing towards patients' satisfaction in hospital foodservice. The finding was consistent with previous studies, which concluded that food quality 
attributes or food properties dimension play a major contribution as the main predictor of overall satisfaction (Lau \& Gregoire, 1998, Wright et al., 2006). This designated that the attributes of food quality become the most influential aspect in patients' judgment towards foodservice. The presence of individual factors in the dimension, which is mostly related to sensory judgment, could explain the current findings. Food quality attributes such as temperature, texture, flavour and appearance are found to be powerful determinants of satisfaction in hospital foods (Hartwell et al., 2007). Another possible explanation for the high influence of food properties dimension is the patient's preconception towards hospital food before even tasting the food. Generally, patients have poor expectation on hospital foods, especially the texture and flavour (Hartwell et al., 2006). This attitude was described as institutionalised stereotyping by previous studies (Cardello, Bell \& Kramer, 1996; Hartwell et al., 2006). This will negatively affect patients' attitudes where patients tend to exaggerate the magnitude of this dimension if they had experienced any improper food quality served. Thus, improvement in the quality of food properties dimension may be able to reduce the poor expectation among patients towards hospital food quality.

In this study, hospital food was able to provide $1869 \pm 213 \mathrm{kcal}$ of energy. This energy value was able to fulfil the minimum requirement of patients. However, the actual energy intake consumed by patients was $1089 \pm 329$ $\mathrm{kcal}$. This value was slightly lower and in agreement with a study by Sahin et al. (2007). Other than that, the percentage of dietary intake indicated that about $72.6 \%$ were able to fulfil their individual requirements for energy intake. This could be due to patients skipping the served foods or eating less due to lesser appetite or other factors. The statistical analysis indicated that male patients tended to consume more hospital foods than female patients. The finding was consistent with Suzana, Kan \& Wan (2002) and Sahin et al. (2007), where a higher percentage of male patients consumed hospital foods compared to female patients. On the contrary, the intake of non-hospital foods was higher in female patients compared to men. This could mean that men were less picky (higher acceptance level) towards foods compared to women. The difference in food intake could be a result of personal acceptance or preference towards hospital foods (Thibault et al., 2011; Johns, Hartwell \& Morgan, 2010). As a consequence, patients chose other sources to fulfil their dietary intakes during hospitalisation. Food consumption during hospitalisation varies from one patient to another. It can be influenced by multiple factors such as cultural, treatment, underlying diseases, physical barrier and foodservice (Naithani et al., 2008, Hartwell et al., 2007).

Several studies had been conducted to determine the dimensions of patients' perceptions towards hospital service especially foodservice (Capra et al., 2005; Hwang \& Desombre, 2003; Dube et al., 1994). However, the number of underlying dimensions of patients' satisfaction is different from one study to another. According to Hwang \& Desombre (2003), there were three dimensions of patients' perceptions towards foodservice, while Capra et al. (2005) found five dimensions of patients' perceptions. Both studies used different methods of analysis, therefore the differences might be due to analysis techniques and duration of the study.

Furthermore, the questionnaire showed a good internal consistency or reliability within the recommended Cronbach's alpha value, ranging from 0.55 to 0.84 for individual dimensions. 
The dimension of food properties showed the largest alpha value compared to other dimensions, suggesting that it is a major influence towards patients' satisfaction (Wright et al., 2006; O'Hara et al., 1997; Stanga et al., 2003). Dimensions such as physical environment, which consisted of several statements, showed minimum alpha value. Thus, improvement of the reliability of this dimension is required in future studies. This is crucial because the role of technical aspects like physical environment is able to influence satisfaction (Hwang \& Desombre, 2003).

\section{CONCLUSION}

The Patients' Satisfaction towards Hospital Foodservice Questionnaire is considered valid and reliable to be used among Malaysian inpatients, based on the statistical analysis. The classification of the four dimensions was able to provide detailed information on the satisfaction level, relationship and influence of these foodservice dimensions, which contributed to satisfaction towards hospital foodservice. This allows suitable strategies to be applied to improve satisfaction ratings. The rating can also be useful to detect changes of patients' satisfaction if a manager changes the foodservice system, foodservice contractor, as well as the diets. The dimension composite scoring indicated that most of the percentage scores were $<80 \%$ based on the recommended value by $\mathrm{MOH}(\mathrm{MOH}$ Malaysia, 2008). This questionnaire will assist hospitals in Malaysia to easily and efficiently obtain a general idea on their patients' health status. In addition, it will help the foodservice personnels to realise the importance of hospital foods in improving the health status of patients during hospitalisation. In addition, the data from this study can be used as baseline for further research regarding hospital foodservice systems.
It should be noted however that the study did have several limitations. First of all, due to logistic reasons, other hospitals could not be included and the study was limited to one hospital only. The major limitation was low response rate among hospitalised patients. One possible reason for low participation among patients was the condition of the patients, as most of those who refused were too ill or in pain. Others were discharged from the hospital before completing all sections of the questionnaire, while others refused to cooperate for fear that their negative comments will affect the treatment they receive from the hospital staffs. Few other patients declined participation saying they needed some privacy. Another limitation was that the trays of patients tended to get lost after tray collection or the foods were mixed with other foods due to improper handling. Thus, to overcome this limitation, the researcher tagged the tray of the respondents to avoid loss or mixture with other trays.

In conclusion, this set of questionnaire should be further analysed and improved to produce a more accurate and reliable tool across populations, time and foodservice systems.

\section{Acknowledgement}

We thank the Director General of $\mathrm{MOH}$ Malaysia, the Medical Research Ethics Committee of the Faculty of Medicine and Health Sciences, Universiti Putra Malaysia, as well as the Director of Hospital Sungai Buloh. In addition, we thank all authors for their valuable contributions.

\section{Authors' contributions}

MB, principal investigator and main author, carried out the survey, prepared and revised the draft manuscript and provided critique; RJ, led the investigation and furnished her expertise in the conception and design of the study, drafting the manuscript, revising and providing critique; NAAM, contributed in the conception and design, data collection, data analysis and interpretation, and preparation of draft manuscript; HAS, participated in the conception and design of the investigation, reviewed the draft manuscript and provided 
critique; MSAK, participated in the conception and design of the investigation, reviewed the draft manuscript and provided critique.

\section{Conflict of interest}

The authors declare no conflict of interest.

\section{References}

Abd Manaf NH \& Phang SN (2007). Patient satisfaction as an indicator of service quality in Malaysian public hospitals. Asian J Qual 10(1):77-87.

Allen P \& Bennett K (2008). SPSS for the health and behavioral sciences. Cengage, Melbourne.

Babakus E \& Mangold G (1991). Adapting the SERVQUAL scale to hospital services: An empirical investigation. Health Serv Res 26:767-786.

Capra S, Wright O, Sardie M \& Bauer J (2005). The acute hospital foodservice patient satisfaction questionnaire: The development of a valid and reliable tool to measure patient satisfaction with acute care hospital foodservices. Foodservice Res Int 16:1-14.

Cardello AV, Bell R \& Kramer FM (1996). Attitudes of consumers toward military and other institutional foods. Food Qual Prefer 7:7-20.

Deluco D \& Cremer M (1990).Consumers' perceptions of hospital food and dietary services. J Am Diet Assoc 90:1711-1715.

Demir C \& Celik Y (2002). Determinants of patient satisfaction in a military teaching hospital. $J$ Healthc Qual 24(2):30-34.

Dickinson A, Welch C, Ager L \& Costar A (2005). Hospital mealtimes: action research for change? Proc Nutr Soc 64:269-75.

Dube L, Trudeau E \& Belanger MC (1994). Determining the complexity of patient satisfaction with foodservices. $\mathrm{J} \mathrm{Am}$ Diet Assoc 94:394-400.

Ganasegeran K, Perianayagam W, ManafRA, Ahmed S, Jadoo A \& Al-dubai SAR (2015). Patient satisfaction in Malaysia's busiest outpatient medical care. Sci World J 2015:714754.

George D \& Mallery P (2003). SPSS for Windows step by step: A simple guide and reference. $4^{\text {th }}$ Edition. Allyn \& Bacon, Boston.

Hartwell HJ, Edwards JSA \& Symonds C (2006). Foodservice in hospital: development of a theoretical model for patient experience and satisfaction using one hospital in the UK National Health Service as a case study. Journal of Foodservice 17(5-6):226-238.
Hartwell HJ, Edwards JSA \& Beavis J (2007). Plate versus bulk trolley food service in a hospital: comparison of patients' satisfaction. Nutrition 23:211-218.

Hinton PR, Brownlow C, McMurray I \& Cozens B (2004). SPSS explained. Routledge Inc., East Sussex.

Hwang LJ \& Desombre T (2003). Gap analysis of patient meal service perceptions. Int $J$ Health Care Qual Assur 16(3):143-153.

Johns N \& Howard A (1998). Customer expectations versus perceptions of service performance in the foodservice industry. Int $J$ Serv Ind Manag 9:248-265.

Johns N, Hartwell H \& Morgan M (2010). Improving the provision of meals in hospital. The patients' viewpoint. Appetite 54(1):181.

Keegan O \& McGee H (2003). A Guide to Hospital Outpatient Satisfaction Surveys. Practical Recommendations and the satisfaction with Outpatient Services (SWOPS) Questionnaire. Royal College of Surgeons in Ireland, Dublin.

Lassen KO, Kruse F \& Bjerrum M (2005). Nutritional care of Danish medical inpatientspatients' perspectives. Scand J Caring Sci 19(3):259-267.

Lau C \& Gregoire MB (1998). Quality ratings of a hospital foodservice department by inpatients and postdischarge patients. J Am Diet Assoc 98:1303-1307.

MOH Malaysia (2018). Patient Satisfaction. Ministry of Health Malaysia. From http:/ / www. moh.gov.my/english.php. [Retrieved October 1 2018].

Naithani S, Thomas JE, Whelan K, Morgan M \& Gulliford MC (2009). Experiences of food access in hospital. A new questionnaire measure. Clin Nutr 28:625-630.

Naithani S, Whelan K, Thomas J, Gulliford M \& Morgan M (2008). Hospital inpatients' experiences of access to food: a qualitative interview and observational study. Health Expect 11:294-303.

Namkung Y \& Jang S (2007). Does food quality really matter in restaurants? Its impact on customer satisfaction and behavioral intentions. J Hosp Tour Res 31(2):387-409.

Norman GR \& Streiner DL (2000). Biostatistics: The bare essentials. $2^{\text {nd }}$ Edition. Hamilton: B.C. Decker Inc., Toronto. 
O'Hara PA, Happer DW, Kangas M, Debeau J, Borsutzky C \& Lernire N (1997). Taste, temperature, and presentation predict satisafaction with foodservice in Canadian continuing-care hospital. J Am Diet Assoc 97:401-405.

Pallant J (2005). SPSS survival manual: a step by step guide to data analysis using SPSS for window (version 12). $2^{\text {nd }}$ Edition. Open University Press, Maidenhead.

Parasuraman A, Zeithaml VA \& Berry LL (1988). SERQUAL: A multiple item scale for measuring consumer perceptions of service quality. $J$ Retail 64:12.

Sahin B, Demir C, Aycicek H \& Cihangiroglu N (2007). Evaluation of factors affecting the food consumption levels of inpatients in a Turkish armed forces training hospital. J Food Qual Prefer18:555-559.

Stanga, Z., Zurflüh, Y., Roselli, M., Sterchi, A. B., Tanner, B., \& Knecht, G. (2003). Hospital food: A survey of patients' perceptions. Clinical Nutrition. https://doi.org/10.1016/S02615614(02)00205-4

Stanga Z, Zurfluh Y, Roselli M, Sterchi AB, Tanner B \& Knecht G (2008). Hospital food: a survey of patients perceptions. Scand $J$ Caring Sci 23(3):241-246.
Suzana S, Kan YC \& Wan CP (2002). Food intakes and preferences of hospitalised geriatric patients. BMC Geriatr 2(3):1-6.

Tabachnick BG \& Fidell LS (2007). Using Multivariate Statistics. $5^{\text {th }}$ Edition. Pearson Education, Inc., Boston.

Thibault R, Chikhi M, Clerc A, Darmon P, Chopard P, Genton L, Kossovsky MP \& Pichard C (2011). Assessment of food intake in hospitalised patients: A 10-year comparative study of a prospective hospital survey. Clin Nutr 30:289296.

Vijayakumaran RK, Eves A \& Lumbers M (2010). Food provision in Malaysian hospitals: practices and implications for patients' food preferences and intake. Paper presented at the meeting EuroCHRIE-The Hospitality and Tourism Educator, Amsterdam.

Wright ORL, Connelly LB \& Capra S (2006). Consumer evaluation of hospital foodservice quality: An empirical investigation. Int $J$ Health Care Qual Assur 19(2):181-194. 